\title{
Foliar secretory structures in Melia azedarach (Meliaceae), a widely cultivated and often invasive tree
}

\author{
Patricia M. Tilney ${ }^{a,},{ }^{*}$ Magda Nel $^{b}$ and Abraham E. van Wyk ${ }^{b, c}$ \\ aDepartment of Botany and Plant Biotechnology, University of Johannesburg, Auckland Park, \\ Johannesburg, South Africa; \\ bDepartment of Plant and Soil Sciences, University of Pretoria, Pretoria, South Africa; \\ 'Biosystematics Research and Biodiversity Collections Division, South African National Biodiversity \\ Institute, Pretoria, South Africa \\ ${ }^{\star}$ Correspondence to: Patricia M. Tilney (pmtilney@uj.ac.za)
}

\begin{abstract}
Melia azedarach (chinaberry; syringa), a tree with bipinnately compound leaves, is one of the most widely cultivated of all tropical trees, but has become naturalised in several parts of the world. New observations are presented on the morphology and anatomy of extrafloral nectaries (EFNs). These should serve as baseline information in ecological studies on the invasiveness of the species, as well as its potential biocontrol. We report, for the first time, extrafloral nectaries (EFNs) on the leaflet lamina, as well as capitate glands on very young leaflets. A sugar analysis of the exudate of the former confirmed it to be nectar. In addition, known EFNs occurring in paired recesses at the petiole base were studied anatomically and developmentally. These so-called paired glands were found to be groups of individual and separate EFNs, for which the new term 'compound EFN' is suggested. Each EFN making up a compound EFN is similar in structure to the laminar EFNs except that they tend to protrude beyond the epidermal surface to a greater degree and to be composed of cells which differ slightly in shape. The secretory tissue of both petiolar and laminar EFNs originates from protoderm and ground tissues, albeit with slightly different initial ell divisions. Capitate glands were found on very young leaflets. Ants were frequent visitors to mainly the petiolar EFNs, less often the laminar ones. Members of the Meliaceae (including M. azedarach) are well known sources of limonoids, compounds with insect antifeedant properties. It is suggested that petiolar and laminar EFNs may attract different preferential nectar feeders, thus providing a first line of indirect defence, resulting in the removal or deterring of potential herbivores even before any damage is inflicted on the plant. Additionally, nectar from the EFNs may protect against co-evolved or other herbivores tolerant of limonoids.
\end{abstract}

KEYWORDS: Anatomy, ants, capitate gland, compound extrafloral nectary, extrafloral nectary, herbivores, invasiveness, mutualism, nectar

\section{Introduction}

Nectar from extrafloral nectaries (EFNs) is a defence trait some plants have evolved as a form of indirect resistance against herbivores (Rico-Gray and Oliveira 2007; Walters 2011; Yamawo et al. 2014). Whereas attracting ants to EFNs is generally considered to be of 
greatest importance to plant defence (Bentley 1977), the ecological effects of this nectar source are much more profound as it is known to not only mediate multi-species interactions across trophic levels (Bezemer et al. 2014; Staab et al. 2016), but may even be herbivore-induced (Heil 2015).

There is mounting evidence that introduced EFN-bearing plant species can in some cases be readily incorporated into native insect-plant networks, suggesting that EFNs may be a trait that facilitates colonisation of new habitats and promotes invasiveness of both insects and plants (Marazzi et al. 2013, and references therein; Heil 2015). Nectar-insect mutualism can be established quickly among non-coevolved (e.g. invasive) species, indicating great potential for also considering EFNs, amongst others, in biocontrol (Heil 2015).

Despite the considerable ecological importance of EFNs, their presence in many floras has not been carefully studied, and much remains to be learned about their structure, biology and function (e.g. Koptur 1994, 2005; Marazzi et al. 2013; Heil 2015). Although EFNs are usually not specifically mentioned as a trait associated with plant invasiveness (e.g. Pyšek and Richardson 2008), many alien invasive woody plants in, for example, southern Africa have EFNs (A.E. van Wyk, University of Pretoria, unpubl. data). Here we report on the morphology, structure and some hitherto overlooked features of EFNs in an horticulturally wellknown tropical tree, and one with invasive tendencies in several parts of the world.

Melia azedarach L., known among others in English as chinaberry, syringa or Persian lilac, is a medium-sized to large deciduous or semi-deciduous tree native to Indomalesia and Australasia (Mabberley 1984). It is one of the most widely cultivated of all tropical trees (Mabberley 1984, 2017; Ahmed and Idris 1997), but has become naturalised in several parts of the world (GISD 2015; Swearingen and Bargeron 2016) including South Africa where it is widespread and invasive, especially in savannah (Henderson 2001; Van Wyk et al. 2008). It belongs to the Meliaceae, a family whose members are sources of limonoids, a group of bitter-tasting phytochemicals with known insect-antifeedant and insecticidal properties (e.g. Roy and Saraf 2006; Fang et al. 2011).

The leaves of $M$. azedarach are clustered towards the ends of the branches and are bipinnately compound (Figure 1A). A pair of sunken glands, orbicular in shape and present at the base of the petiole (but not on the leaflets) was reported by Jacobs (1961), but this reference appears to have been overlooked by subsequent workers on EFNs in the family, most likely because they were not specifically called EFNs. Yamawo (2015), for example, reported their presence as a first record for the species, although in reality he was the first to have confirmed that they secrete nectar. Recently we described EFNs and colleters present in Ekebergia capensis Sparmm., another member of the Meliaceae (Tilney et al. 2018). In the latter study we also recorded the microscopic structure of the EFNs of all known members of the family previously studied. When comparing the leaves of E. capensis with those of M. azedarach, EFNs and capitate glands were discovered also to be present on the leaflets of the latter. However, an anatomical study of M. azedarach and M. dubia Cav. (now considered a synonym of $M$. azedarach) by Saentrong (1990) makes no mention of these structures (at least in the Abstract). Likewise Abdel-Hameed (2014) does not mention foliar EFNs in $M$. azedarach, but he briefly refers to the presence of 'glandular trichomes with multicellular foot and head'.

This article presents, as far as we can ascertain, the first report of laminar EFNs and capitate glands (associated with very young leaflets) in M. azedarach. We describe their distribution, anatomy and development, as well as the sugar composition of the EFN 

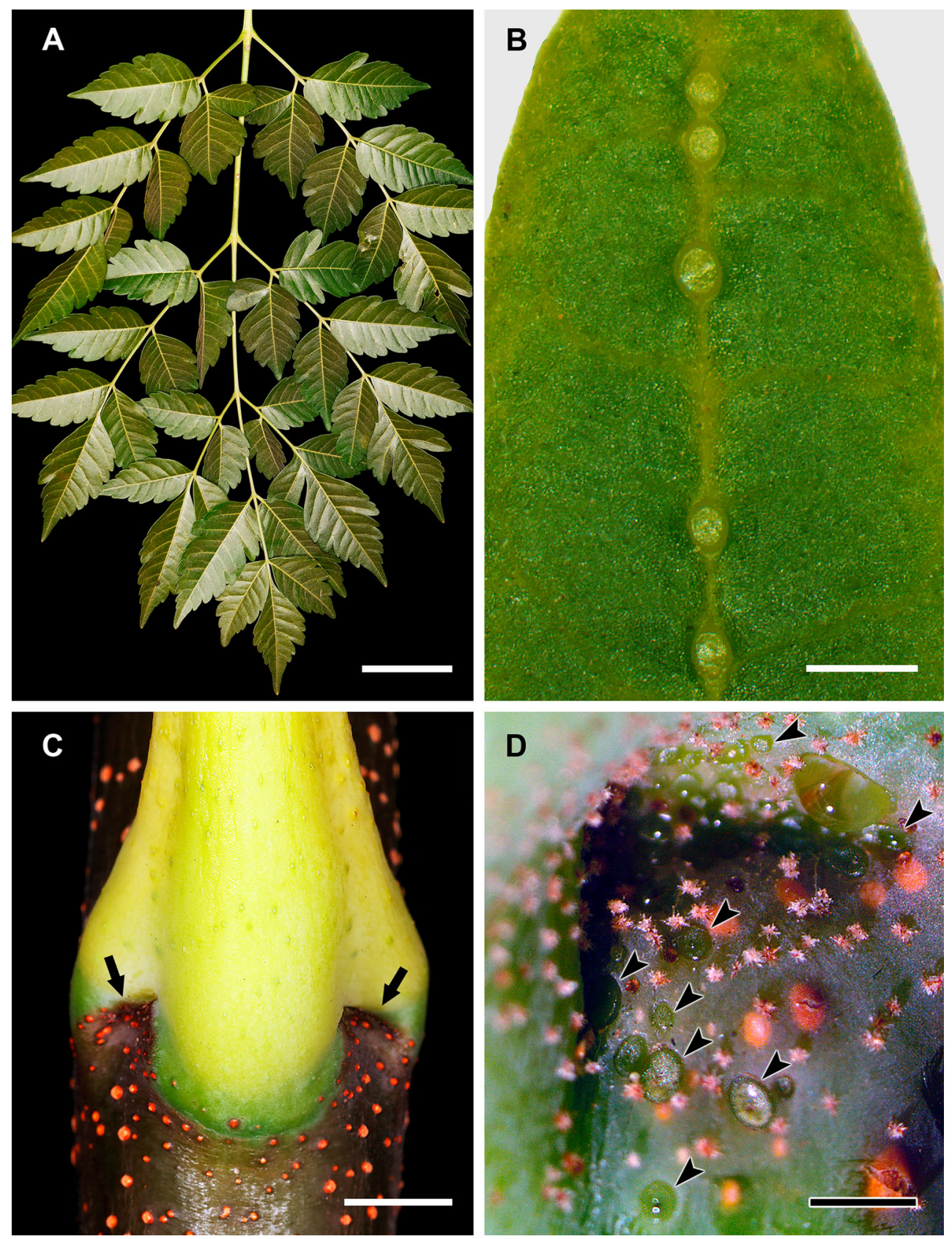

Figure 1. Morphology of the leaves and extrafloral nectaries of Melia azedarach. A, Portion of distal part of a bipinnately compound leaf. Scale bar $=50 \mathrm{~mm}$; $\mathbf{B}$, adaxial surface of a leaflet apex showing five laminar nectaries on the midrib. Scale bar $=500 \mu \mathrm{m} ; \mathbf{C}$, thickened base of a petiole showing the two recesses at the point of attachment to the stem. Many knob-like lenticels can be seen on the stem, but macroscopically the extrafloral nectaries in the recesses are not visible. Scale bar $=3 \mathrm{~mm}$; $\mathbf{D}$, enlargement of a recess at base of petiole showing several extrafloral nectaries, including an upper right hand one which is covered by a drop of nectar. Interspersed among the extrafloral nectaries are lenticels and tufted stellate hairs. Scale bar $=1 \mathrm{~mm}$. Arrow $=$ recess at base of petiole; arrowhead $=$ extrafloral nectary. 
secretion. Comparisons are made with other members of the family that have been studied anatomically and for extrafloral nectar sugars to date. As anatomical studies were not included in previous reports on the paired basal petiolar glands, their structure and development were also studied and reported on here. Based on our findings, the new term 'compound EFN' is proposed. We also report on observations relating to nectar consumers, and highlight the availability of nectar from EFNs as a potential trait associated with invasiveness in alien plants, and its implications.

\section{. BPERIBOENPU PET}

\section{Plant material, visitors and number of EFNs}

Melia azedarach trees are abundant and widespread in South Africa and observations as to visitors on the leaves were made wherever possible. EFNs on the petioles and leaflets were obtained from a Johannesburg garden tree and photographed with an Olympus SZX 16 stereomicroscope using an Olympus ColorView Soft Imaging System. The number of EFNs was counted on a total of five leaves, representing 29 pinnae and 200 pinnules (leaflets), from three trees growing in different parts of Pretoria (on pavements in Rietondale and Mountain View, and in the parking lot outside the Plant Sciences Complex, University of Pretoria).

\section{Scanning electron microscopy}

For scanning electron microscopy (SEM), fresh and dried leaflet and petiole material of pavement trees growing in Pretoria (Die Wilgers) and Johannesburg (Melville) respectively was studied. Leaves were air-dried at room temperature whilst lightly pressed between sheets of cardboard to keep them flat. Fresh and dried leaves were first examined under a stereomicroscope to identify EFNs. Suitable portions containing EFNs and measuring about $5 \mathrm{~mm}^{2}$ were cut with a razor blade from mature leaflets or the basal portion of the petiole. These were mounted on a conductive adhesive pad, placed in a charge reduction sample holder and viewed, uncoated, in a desktop SEM (Phenom Pure+) at $5 \mathrm{kv}$.

\section{Light microscopy}

For light microscopy, small portions of leaflets (from street and garden trees in Illovo and Melville, Johannesburg) in different stages of development, each bearing an EFN, were preserved in FAA (formalin-acetic acid-alcohol), then dehydrated, infiltrated with glycol methacrylate (GMA) and embedded in gelatin capsules containing GMA according to the method of Feder and O'Brien (1968). Transverse sections, 3-5 $\mu \mathrm{m}$ thick, were cut with a Porter Blüm ultramicrotome and placed in droplets of water on glass slides. After drying overnight on a slide warmer, some of the slides were stained with Schiff s reagent and toluidine blue (Feder and O'Brien 1968), and then mounted with Entellan (Product 7961, E. Merck). The unstained slides were examined under polarised light particularly to facilitate the study of calcium oxalate crystals. Very young whole leaflets were similarly treated as well as gland-containing portions of the base of petioles. 


\section{Nectar composition}

To determine the sugar composition of the secretion of the laminar glands, leafy twigs from trees growing in Denyssen Avenue, Mountain View, Pretoria and in the parking lot outside the Plant Sciences Complex, University of Pretoria, were collected on 30 and 31 May 2016, respectively. The cut stems were placed in jars with water, and the foliage covered with plastic bags to create a moist atmosphere and, after several hours, the liquid exudate from the glands was collected on Whatman No. 1 filter paper and stored in a fridge. The samples were extracted with $50 \%$ acetonitrile $(0.5 \mathrm{~mL})$, sonicated, centrifuged and transferred to vials. The sugar composition (glucose, fructose and sucrose) was determined using the fast screening HILIC-MS method of Stander et al. (2013). The percentage of each of these sugars was calculated as were the glucose/fructose and glucose + fructose/sucrose ratios.

\section{Results}

\section{Laminar EFNs: appearance, distribution and secretions}

Laminar EFNs in M. azedarach are minute (usually about 200-300 $\mu \mathrm{m}$ in diameter), circular, green and difficult to detect without magnification (Figures 1B, 2A). These glands are generally slightly raised or more or less level with the leaflet surface, corresponding to the 'Flachnektarien' of Zimmermann (1932) or 'flat nectaries' of Elias (1983). They may occur on both surfaces of the leaflets but are more frequent on the adaxial side. Averages of 3.4 adaxially and 1.0 abaxially per leaflet (pinnule) were noted with ranges of $0-8$ adaxially and $0-5$ abaxially. They are mostly found on or close to the midrib towards the apex of the leaflets (Figure 1B). Secretions from the laminar EFNs were not readily detected without magnification and occurred as single droplets on the EFNs. They were often present even
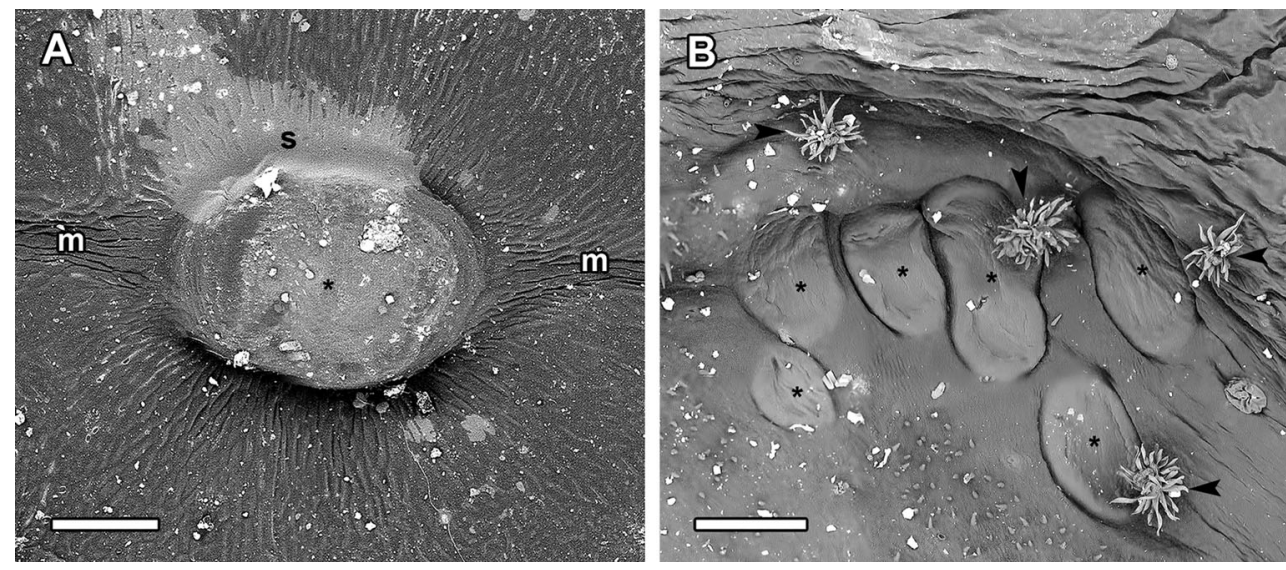

Figure 2. Micromorphology of foliar extrafloral nectaries in Melia azedarach. A, Adaxial surface of leaflet (fresh material) with a laminar gland partly covered by dried remains of secretion. Note absence of stomata on the secretory pole. Scale bar $=100 \mu \mathrm{m}$; B, petiolar recess (air-dried material) with several nectary glands arranged in close proximity, the latter collectively representing a compound extrafloral nectary. The secretory poles of the glands lack stomata. Scale bar $=200 \mu \mathrm{m}$. Arrowhead = stellate hair; asterisk = extrafloral nectary. $\mathrm{m}$, midrib of leaflet; $\mathrm{s}$, dried remains of secretion. 
on senescent leaflets about to be shed in autumn. On the leaflet laminae, ants of various sizes were often seen but nearly always feeding singly at an EFN.

\section{Petiolar EFNs: appearance and secretions}

Each of the paired recesses at the base of the petiole (Figure 1C) was found to house several discrete circular EFNs arranged in an irregular group (Figures 1D, 2B). These are of the same broad morphological type as the laminar EFNs and are not readily discernible macroscopically being of a similar green colour to the surrounding parts of the recess. In addition, stellate hairs which densely cover very young developing leaves often persist in the hollows amongst the individual EFNs (Figures 1D, 2B). During the growing season, several separate droplets of exudate (Figure 1D) were frequently clearly visible in each recess, each from an individual EFN. These droplets may coalesce, resulting in a single drop which more or less covers the entire recess. Larger numbers of feeding ants were invariably observed congregated in each recess than on the laminar EFNs.

\section{Laminar EFNs: transverse section}

In transverse sections of the leaflet lamina, the EFNs are seen to be more or less level or slightly concave with the leaflet surface (Figure 3A-C). In actively secreting glands the epidermis is usually not distinguishable from the rest of the secretory tissue, which is densely cytoplasmic (Figure 3A-B). At the periphery of the EFN, lipophilic material that stains the same colour as the cuticle is present in large amounts and appears to embed the cells in this region (Figure $3 \mathrm{~A}-\mathrm{B}$ ). The cuticle seems to be very thin or not discernible in the centre of the EFN (Figure 3A). Stomata are absent despite being abundant abaxially (absent adaxially) (Figure 2A). The secretory cells are generally isodiametric to irregularly-shaped. The outermost portion of the EFN stains darkish blue while the innermost cells have brown contents (presumably tanniniferous; Figure 3C), which stain greenish blue and resemble some of the contents of the mesophyll cells in other parts of the leaflet (Figure 3A-B). Adjacent to the EFNs, the mesophyll cells tend to be relatively small, isodiametric, dense and more tightly packed. Druse crystals of calcium oxalate are not markedly more abundant in the cells surrounding the EFNs than in the palisade and spongy mesophyll where they may be frequent; for example, in transverse sections, up to five crystal-containing cells arranged in a column interspersed with typical anticlinally elongated palisade cells may be seen (Figure 3C). The phloem of the vascular tissue is relatively well developed and very close to, if not in direct contact with, the innermost cells of the EFN (Figure 4A-B).

\section{Petiolar EFNs: transverse section}

The EFNs and surrounding tissue at the petiole base usually protrude a short distance beyond the recess surface (Figures 2B, 5A). A more or less distinct epidermis is often visible in developing EFNs (Figure 5B). In actively secreting EFNs, fine protoplasmic extensions through the cuticle may be seen. The cuticle is well defined and generally thick, and lipophilic material staining the same as the cuticle is concentrated at the periphery of the EFN (Figure 5A-B). The cuticle is relatively thin or not discernible in the middle of the secretory pole of the EFN. The secretory cells are sometimes isodiametric 

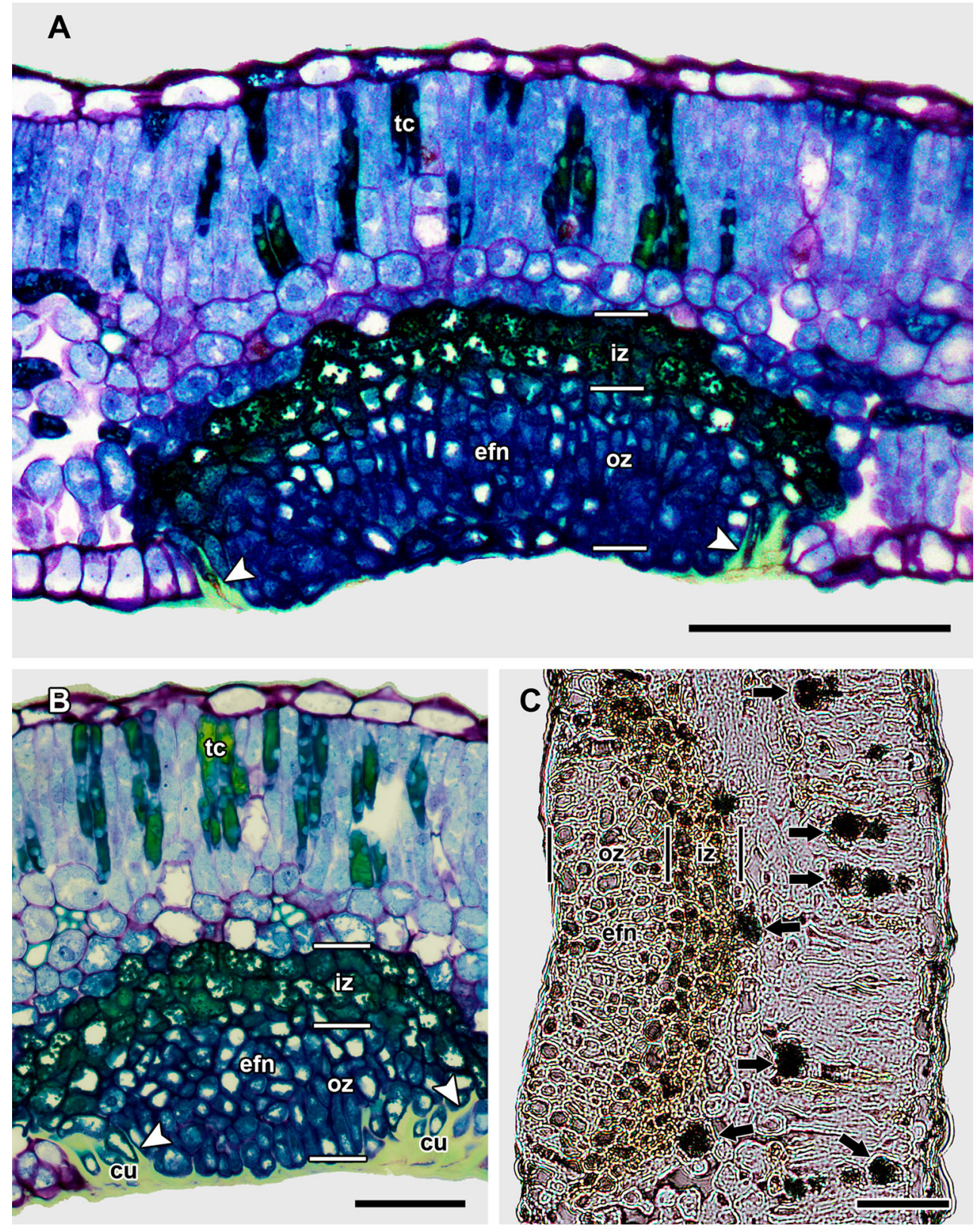

Figure 3. Anatomy of laminar nectaries in Melia azedarach. Leaflets in transverse section, with nectary on abaxial side. A, Mid-sagittal view of nectary. Note differentiation of secretory tissue in an inner zone (greenish blue) and an outer zone (darkish blue). At the periphery of the outer zone, lipophilic material that stains the same colour as the cuticle is present and embeds the cells in this region. Scale bar = $100 \mu \mathrm{m}$; B, parasagittal view of a nectary, with clearly differentiated outer and inner zones, and the peripheral intrusion of cuticular material even more prominent. Scale bar $=100 \mu \mathrm{m} ; \mathbf{C}$, unstained section showing nectary in mid-sagittal plane, with brownish inner zone and scattered druses of calcium oxalate (blackish) in mesophyll surrounding the secretory tissues. Scale bar $=50 \mu \mathrm{m}$. Arrowhead = 'strands' of cuticular (lipophilic) material; arrow = druse crystal of calcium oxalate. cu, cuticular (lipophilic) material; efn, extrafloral nectary; iz, inner zone of nectary; oz, outer zone of nectary; tc, tanniniferous palisade cells. 

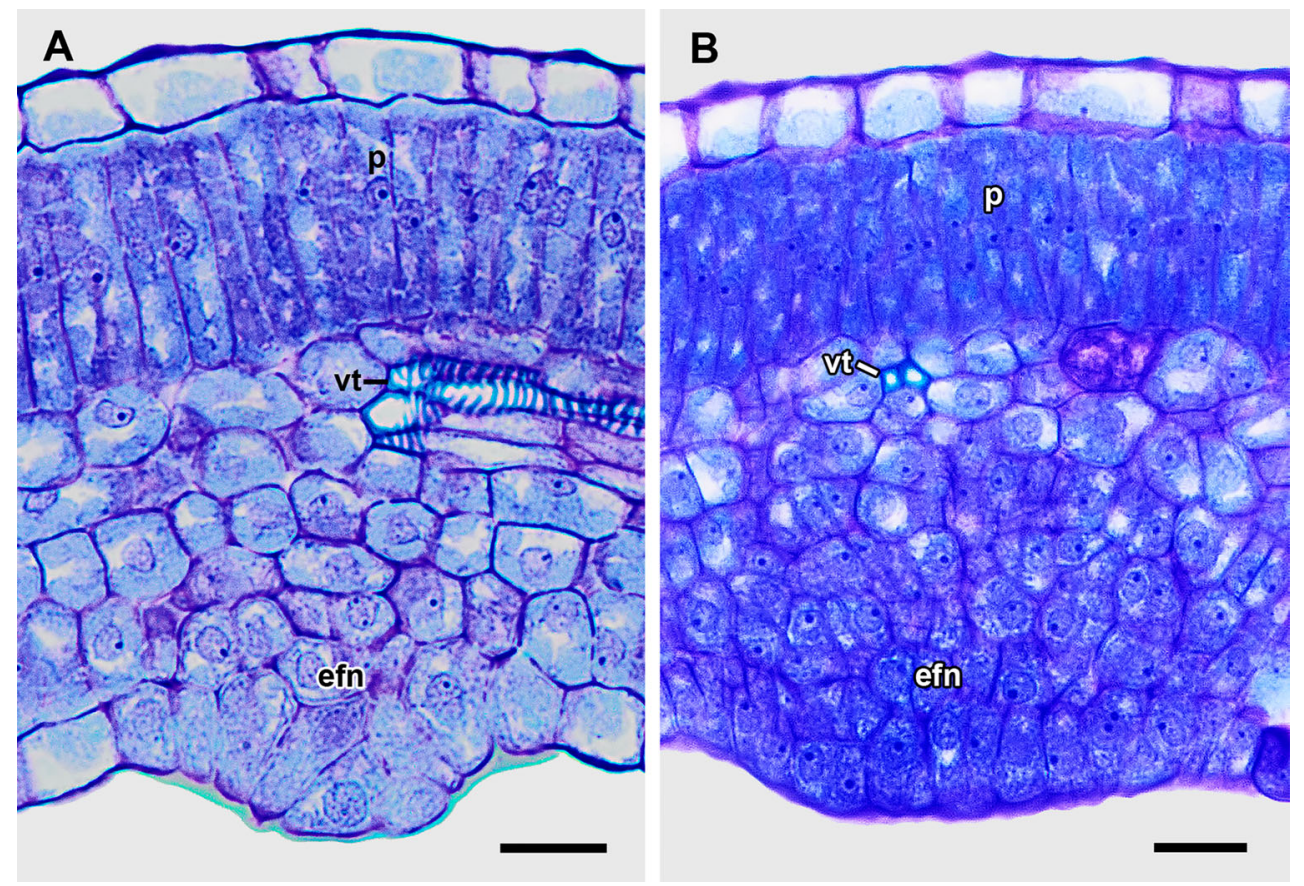

Figure 4. Initial stages in the development of laminar nectaries in Melia azedarach. Leaflets in transverse section, with developing nectary on abaxial side. A, Very young nectary developing from protoderm and ground tissues, usually in close proximity to vascular tissue; initial cell divisions take place in various directions; $\mathbf{B}$, developing nectary slightly older than the one depicted in A, but secretory tissue not yet differentiated into two zones. efn, extrafloral nectary; $p$, palisade parenchyma; vt, vascular tissue. Scale bars $=100 \mu \mathrm{m}$.

to irregular but frequently somewhat anticlinally elongated especially towards the outside (Figure 5A). The innermost region of the EFN stains darker than the outermost and resembles the contents (probably tanniniferous) of some surrounding cells (Figure 5A); in unstained sections these are a similar brown colour. A zone of relatively dense isodiametric cells surrounds the EFN (Figure 5A). Several cell layers separate the innermost portion of the EFN from the vascular tissue. Druse crystals are generally present in small numbers in parenchyma surrounding the gland.

\section{Laminar and petiolar EFNs: early development}

The secretory tissue of the laminar EFNs originates from protoderm and ground tissues (Figure 4A-B). The initial divisions take place in various directions. Druse crystals associated with the mesophyll were not present in the early stages of development and were first seen in the phloem of the midrib. The EFNs in the recesses at the base of the petiole are formed essentially by several periclinal divisions of the cell layer immediately below the protoderm giving rise to a structure which usually protrudes a short distance beyond the adjacent areas (Figure 5B). A distinct uniseriate epidermis is visible during much of the development (Figure 5B). 

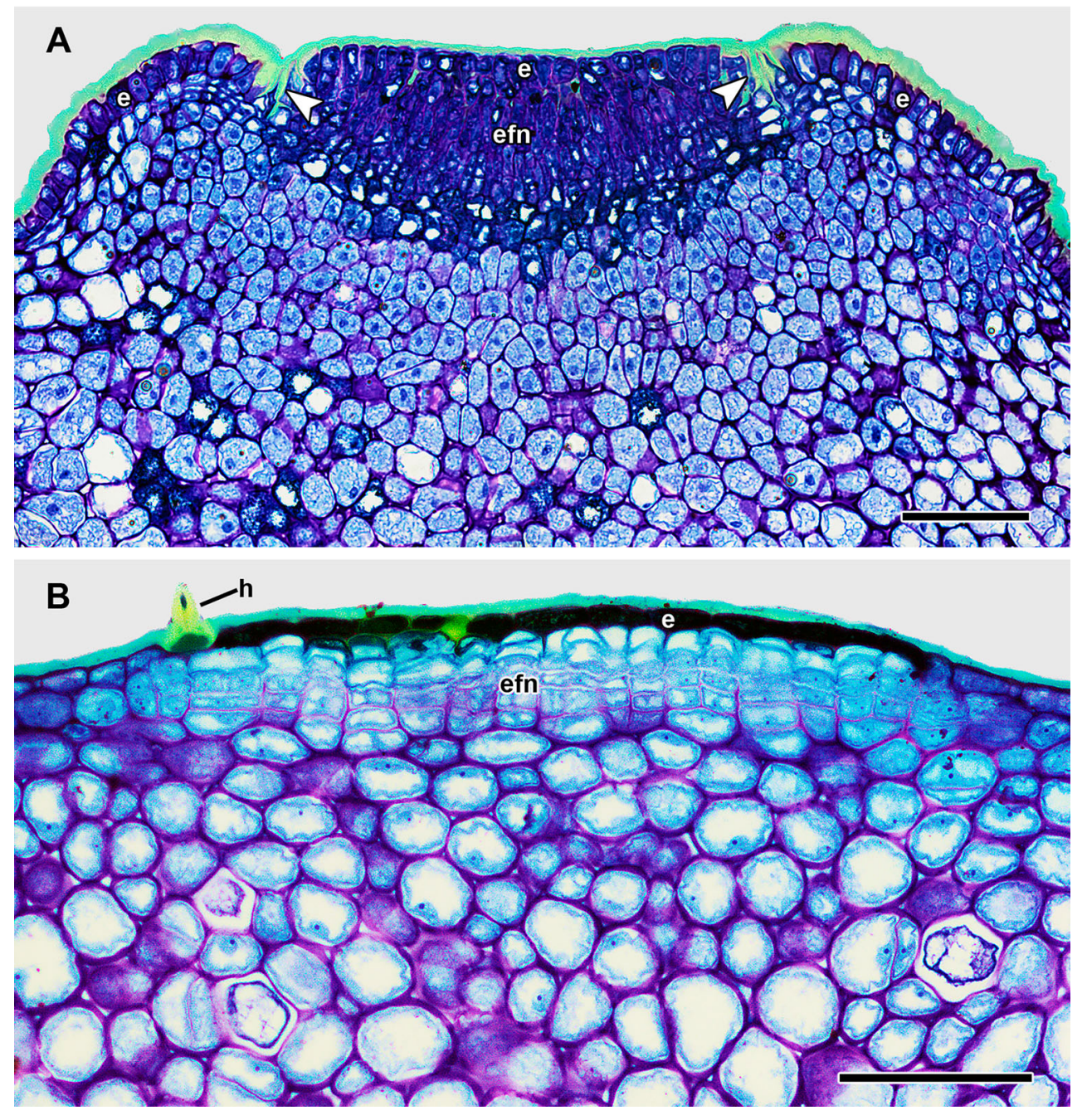

Figure 5. Anatomy and initial stages in the development of petiolar nectaries in Melia azedarach. Transverse sections of nectaries in recesses at base of petiole. A, Parasagittal view of mature nectary, showing secretory and surrounding tissue protruding a short distance beyond the recess surface. Note cuticular (lipophilic) material intruding among peripheral secretory cells; B, mid-sagittal view of young developing nectary. Secretory tissue is derived from several mainly periclinal divisions of the cell layer immediately below the protoderm. A uniseriate epidermis, its cells often strongly tanniniferous, is present above developing glands. Arrowhead = cuticular 'strand'. e, tanniniferous epidermis; efn, extrafloral nectary; $h$, basal portion of a stellate hair. Scale bars $=100 \mu \mathrm{m}$.

\section{Capitate glands, simple and stellate hairs}

In very young leaflets (when still conduplicate), capitate glands were present concentrated along the upper surface of the midrib and also scattered on the lower surface (Figure 6A-B). They are also present abaxially and adaxially on the leaflet lamina. These glands have a stalk of about 4 to 12 cells and a multicellular head composed mainly of cells with dense cytoplasm (Figure 6B). Unicellular hairs are located adaxially 

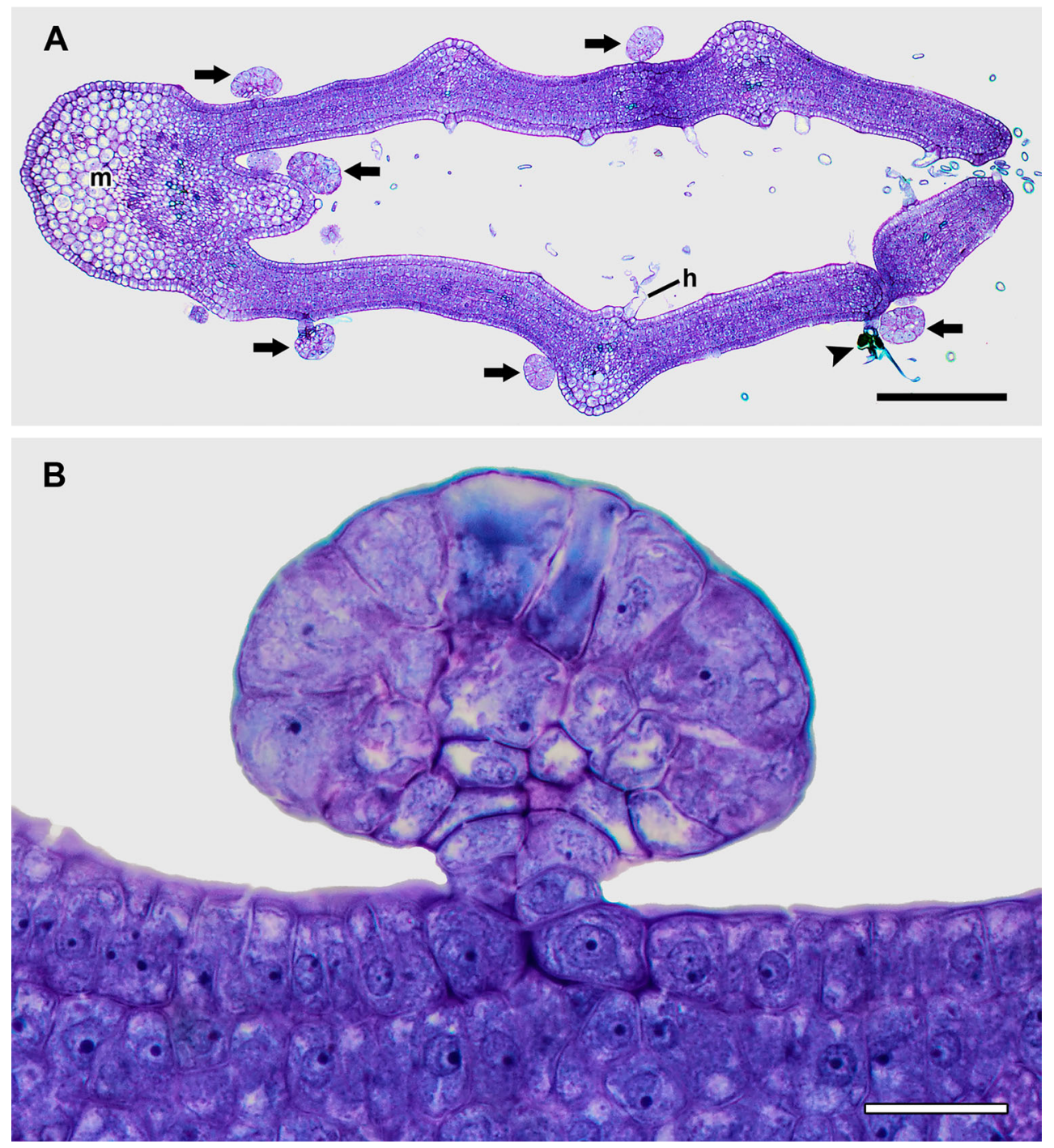

Figure 6. Glandular capitate hairs on developing leaflet of Melia azedarach. Transverse sections of a young, conduplicate leaflet. A, Capitate glands are concentrated along the adaxial surface of the midrib and are also scattered mainly on the abaxial surface. Unicellular hairs are located mainly adaxially and are most often associated with veins. Stellate hairs, which are abundant abaxially on very young leaflets, are quickly shed as the leaflets expand. Scale bar $=200 \mu \mathrm{m} ; \mathbf{B}$, details of a capitate gland on the abaxial surface showing the short stalk of about 4 to 12 cells and a multicellular head composed mainly of cells with dense cytoplasm. Scale bar $=20 \mu \mathrm{m}$. Arrowhead $=$ parts of a stellate hair; arrow = capitate gland. $h$, unicellular hair; $m$, midrib.

(where they are more abundant) and abaxially, and are usually associated with veins (Figure 6A). Some remaining stellate hairs may also be visible abaxially (Figure 6A).

\section{Nectar composition}

The sugar analysis of two samples of laminar EFN nectar from different trees revealed the following: Mountain View, Pretoria sample was composed of glucose 33\%, fructose 36\% 
and sucrose $31 \%$; and the Pretoria University campus sample was composed of glucose $37.5 \%$, fructose $37.5 \%$ and sucrose $25 \%$. The ratio of glucose:fructose varies from 0.90 to 0.92 , whereas the ratio of glucose + fructose:sucrose varies from 2.3 to 3.4 .

\section{Discussion}

\section{Morphology and anatomy of secretory structures}

The small size of the laminar EFNs in M. azedarach, their green colour and essentially flattened structure, together with their occurrence amongst stellate hairs, are probably the main reasons why these glands have remained unreported for so long in a tree which is common in many parts of the world. Already in 1985, Lersten and Pohl suggested that EFNs are widespread in Meliaceae, rather than rare as was thought by earlier researchers such as Elias (1983). Melia azedarach has laminar EFNs on both leaflet surfaces as in some other Meliaceae taxa; in other members they are confined to the abaxial side (e.g. Weber et al. 2015). In Ekebergia capenis the EFNs tend to be concentrated distally on the leaflets (Tilney et al. 2018) but in M. azedarach this is even more marked. The general pattern for foliar EFNs is to be placed towards the base of the leaf/leaflet, often at the position where the petiole is attached to the lamina. As in E. capensis (Tilney et al. 2018) and Cedrela fissilis Vell. (Paiva et al. 2007), droplets of secretion were present even in old senescing leaves. This more distal arrangement of laminar EFNs in some Meliaceae may well be advantageous in ensuring that visiting ants patrol most of the leaflet surface before reaching the nectar reward (but also see another possibility under 'Ecological and functional significance of EFNs', below).

Glands on the swollen petiole base of $M$. azedarach leaves were reported and illustrated by Jacobs (1961) as two prominent recesses, a reference apparently overlooked by subsequent researchers on the Meliaceae EFNs. Jacobs describes these glands as being 'mostly lacking and obscure'. One of the characters he uses in his key to distinguish between the genera Melia L. and Azadirachta A.Juss. is 'base of the petiole occasionally with one pair of sunken orbicular glands' for Melia, and 'base of the petiole mostly with one pair of orbicular glands and one pair of elongate glands below these' for Azadirachta. Mabberley (1984), in his monograph of the genus Melia, does not make any mention of EFNs in the group. Yamawo (2015) reported EFNs in M. azedarach at the bases of all petioles of young plants, not in mature plants. However, we found them on most leaves of all the trees we observed, irrespective of their age.

The papers by Jacobs (1961) and Yamawo (2015) appear to be the only records for Meliaceae of petiolar glands in a consistent position and number. However, it does not seem that the presence of several separate EFNs grouped together in each recess of the swollen petiolar base, as found in the material used in the present study, was reported by either of them. We here propose the term 'compound EFN' to refer to such an area composed of several individual EFNs arranged in close proximity and occurring in a fixed position. It must, however, be pointed out that $M$. azedarach is comprised of a bewildering diversity of infraspecific forms and cultivars-the species has been in cultivation for over 2500 years (Mabberley 1984). The EFNs may well be showing different patterns of variation among these infraspecific taxa, the latter which is usually not specified in publications. Although EFNs on petioles have been recorded in other members of the Meliaceae; for example, in species of Swietenia Jacq. by Lersten and Rugenstein (1982), in 
Guarea macrophylla Vahl by Morellato and Oliviera (1994) and in Ekebergia capensis (Tilney et al. 2018), they appear to be scattered and similar to those elsewhere on the leaves.

As in all other anatomical studies of EFNs in Meliaceae to date, stomata are absent from the secretory pole of the laminar EFNs of M. azedarach. The periphery of the sunken portion of EFNs is characterised by an abundance of amorphous lipophilic material staining similar to that of the cuticle. If one assumes this material to contain cutin, a possible function of containing the secretion produced by the outer cell layers (which are the most densely cytoplasmic) by preventing 'leakage' to surrounding tissues would seem appropriate. However, in our study of the EFNs of Ekebergia capensis (Tilney et al. 2018), similar cuticular (lipophilic) material is deposited outside the cell walls and pervades much of the nectariferous tissue but in such a way as to give the appearance, in transverse sections of the leaflet, of radial strands traversing the gland. It would seem that, if this material were impervious, it would hinder the transfer of the secretion within the EFN especially in a lateral direction. It was suggested by Fahn (1979) that analogous cell wall impregnation by cutin or suberin in nectariferous tissue may, in some way, facilitate symplastic transport within the EFN. It seems that the functional significance of these cuticular (lipophilic) deposits deserves further investigation.

EFNs of Melia azedarach, like those in some other members of the family, lack a distinct epidermis on the secretory pole; for example, Swietenia species (Lersten and Rugenstein 1982), Guarea macrophylla (Morellato and Oliviera 1994) and Ekebergia capensis (Tilney et al. 2018). The outermost portion of the glandular tissue in M. azedarach stains more intensely than the innermost, the cells of which resemble some of the ordinary mesophyll cells. Differences in staining and/or appearance in different parts of the EFN have been reported in other members of Meliaceae such as Cedrela fissilis (Paiva et al. 2007). In Ekebergia capensis, concentrations of pink pigments (presumably anthocyanins) were found in the innermost cells of some EFNs (Tilney et al. 2018). A sheathing layer of thick-walled cells around the gland is absent in M. azedarach as in, for example, Cipadessa baccifera (Roth) Miq. (Lersten and Pohl 1985). In M. azedarach the EFNs are in direct contact with, or very close to, the vascular tissue. Such a very close connection has not been reported in other Meliaceae taxa studied.

Druse crystals, specifically in cells surrounding EFNs, have been reported by Paiva et al. (2007) in Cedrela fissilis and by Tilney et al. (2018) in Ekebergia capensis although Metcalfe and Chalk (1950) stated that solitary and druse crystals are common in tissues of all the organs of the family. Paiva and Machado (2005) mention that the presence of such calcium oxalate crystals may be indicative of cells active in symplastic transport. It is, for example, known that calcium ions inhibit plasma membrane ATPase which is involved in the transport of sucrose in plants. By sequestering calcium the crystals of calcium oxalate may remove calcium to facilitate the transport of sucrose (Nepi 2007 and references therein). Escalante-Pérez and Heil (2012) discuss the possible relationships between the structure and function of EFNs.

The individual EFNs making up the paired compound EFNs at the petiole base have essentially the same general structure as the laminar EFNs. However, they usually protrude slightly beyond the epidermis of the surrounding part of the recess and the secretory pole of each EFN has a distinct epidermis. Some of the epidermal cells have fine cytoplasmic extensions traversing the cuticle and may play a role in facilitating the release of the 
secretion. In addition, the petiolar EFNs are not particularly close to the vascular tissue. Their initiation also appears to differ and the mainly periclinal divisions would account for them tending to protrude and to retain a distinct epidermis.

The glandular hairs on very young leaflets in $M$. azedarach differ from those described as colleters in E. capensis (Tilney et al. 2018) in being present on the abaxial as well as the adaxial surfaces of the lamina, in having stalks, and no inner core of cells. Moreover, they appear to be exclusively epidermal in origin, thus do not qualify as emergences which are structures derived from both epidermal and subepidermal tissue (Evert 2006). Hence they are here described as capitate glands rather than colleters. Elsewhere in the Meliaceae rather similar-looking multicellular glandular hairs have previously been reported on the leaves of Nymania capensis (Thunb.) Lindb. (Dahlgren and Van Wyk 1988). However, the distinction between glandular hairs and colleters is not always straightforward (Thomas 1991; Evert 2006). It remains to be established whether the capitate hairs of young developing leaflets in $M$. azedarach are homologous or not with the colleters in E. capensis. It is also not clear whether the glandular trichomes briefly mentioned by Abdel-Hameed (2014) as being present in M. azedarach, are the same structures we encountered on very young, developing leaflets.

\section{Ecological and functional significance of EFNs}

The concentration of several individual EFNs in the petiole base recesses may well account for the larger number of ants usually observed in this position as compared to that of the individual laminar EFNs (but see below for another possible explanation). We recorded a variety of ants at the EFNs which concurs with the observations of Yamawo (2015) who identified five ant species and a click beetle (Coleoptera: Elateridae) visiting the compound EFNs at the petiolar base. Glucose, fructose and sucrose are present in the laminar extrafloral nectar. The relative percentages of these sugars are similar to what was found in E. capensis (Tilney et al. 2018). This appears to be the only extrafloral sugar analysis for $M$. azedarach. Although even single sugars in the nectar can determine the spectrum of visitors to EFNs (Heil et al. 2005), other components such as amino acids (GonzálezTeuber and Heil 2009a, 2009b; Heil 2011; Escalante-Pérez and Heil 2012; Nepi et al. 2012) are also known to be important determinants. Therefore a future analysis of the amino acids is recommended. Yamawo (2015) reported that a single petiolar EFN in a Japanese plant of $M$. azedarach secreted nectar at an average rate of $1.6 \pm 0.9 \mu \mathrm{L}$ per $24 \mathrm{~h}$. However, this measurement is ambiguous as it would seem that Yamawo interpreted the whole petiolar recess as a single EFN, whereas it is a compound structure.

The generally accepted function of EFNs is to attract predatory or parasitoid arthropods, mainly ants and wasps, but also spiders, mites, bugs and predatory beetles, by providing them with food in the form of nectar (e.g. Koptur 2005; Heil 2015). These nectar-feeders, in turn, protect the plant from herbivore attack. Hitherto relatively scant attention has been given to the effects of EFN distribution and structure on specific nectar-feeders. Studies on ant-visitors to foliar EFNs of Passiflora (Passifloraceae) have demonstrated that plants sharing the same habitat and accessible to the same members of the ant community may differ in patterns of visitation by ants. This is presumably due to differences in nectary structure, secretion rate and nectar composition (Smiley 1978; Bentley 1983; Apple and Feener 2001). In some species of Passiflora, EFNs are avoided by ants and are 
preferentially visited by parasitoid wasps that breed on the caterpillars of Heliconius butterflies, the latter for which members of Passiflora are the larval food plant. A similar avoidance of actively secreting EFNs by ants was also noticed by us in E. capensis (Meliaceae) (Tilney et al. 2018). In M. azedarach the paired compound EFNs at the petiole base are actively visited by ants (Yamawo 2015; the present study). Although ants were noticed feeding on the smaller, laminar EFNs towards the leaflet apices, they were clearly less often visited than the petiolar EFNs. The concentration of the laminar EFNs on the distal portion of the leaflets suggests that the main nectar consumers of these glands may be flying rather than crawling insects. Studies on potential consumers of EFN nectar in the native range of $M$. azedarach should consider the possibility that the two types of nectaries may well be preferentially visited by two different assemblages of nectar feeders.

Since M. azedarach leaves contain limonoids, which make them bitter and are insectantifeedants, the purpose of the EFNs must somehow complement this direct chemical defence. The petiolar base EFNs, in particular, produce much nectar and ant activity was frequently observed. To form and sustain such active EFNs would obviously require much investment by the plant. It is suggested that EFNs provide a first line of indirect defence, resulting in the removal or deterring of potential herbivores even before any damage is inflicted on the plant. Additionally, the EFNs may protect against co-evolved or other herbivores which can tolerate limonoids, the latter being the most distinctive group of secondary metabolites in the plant order Sapindales/Rutales (Champagne et al. 1992), of which Meliaceae is a member. Such chemical tolerance/resistance is quite evident considering, for example, the many insect pests on commercially grown members of the citrus family (Rutaceae) (e.g. Dreistadt 2012). No doubt, however, the limonoids and EFNs may well have contributed to the success of this plant in various parts of the world, including its success as an invader.

Existing studies on EFNs in the invasive context have focused mainly on the consequences for native EFN-producing plants when invasive ants replace native ants (e.g. Lach 2003; Ness and Bronstein 2004; Lach and Hoffmann 2011; Savage and Whitney 2011; for a review and more references, see Heil 2015). Nectar is a non-specific food source, generally available to consumers of nectar outside a plant species' native range. Yet, one of the most widely claimed potential reasons as to why plants become invasive is the fact that when plants are introduced to new continents, they leave many associated herbivores and pathogens behind, thus resulting in an increase in their competitive ability; the so-called 'enemy release hypothesis' (Elton 1958; Keane and Crawley 2002; Blumenthal 2006). However, the success of invasive plant species in their new range also depends on the interactions with herbivores (Bezemer et al. 2014, and references therein). For example, invasive plants may generate novel interactions with native insects that can ultimately lead to host plant shifts as well as influence interactions between insects and native plants (Lach et al. 2010). We argue that once introduced plants are released from many or all of their natural enemies, their EFNs may actually provide them with additional indirect protection, this time from potential herbivores in their new environment.

One of the very few ecological studies on an invader plant species with both chemical (cyanogenesis) and EFN defences involved Prunus laurocerasus L. (Rosaceae), an evergreen shrub to small tree widely used in landscaping in temperate zones (Kautz et al. 2017). This Asian species has become an important invader in the Pacific Northwest. It was concluded by Kautz et al. (2017) that the additional inducible indirect defence 
imparted to the species by nectar from the EFNs significantly contributes to the success of English laurel as an invasive species. Heil (2015) hypothesised that extrafloral nectar, rather than chemical defences, helps prepare plants for possible herbivores which do not share a co-evolutionary history. In a number of recent studies which have included crop plants, EFNs have shown much potential for environmentally-friendly biological pest control (e.g. de la Fuente and Marquis 1999; Unsicker et al. 2009; Larsen and Philpott 2010; Hernandez et al. 2013; Stenberg et al. 2015; Jones et al. 2016).

\section{Conclusions}

EFNs, laminar and petiolar, were present on all investigated $M$. azedarach trees. The laminar EFNs occur singly whereas those in the paired recesses at the petiolar base are in discrete groups, here termed 'compound EFNs'. The individual EFNs of the compound EFNs differ very slightly from the laminar EFNs developmentally and structurally. Ants frequently visited both types of EFNs but were most common and abundant on the compound EFNs. The presence of highly active EFNs together with a chemical defence in the form of limonoids may well account for some of the success of this tree as an invader. A brief consideration of the ecological significance of nectar from EFNs as an indirect form of resistance against herbivores suggests that the role of EFNs as a potential invasive plant trait offers considerable scope for further study. Our observations on the morphology and anatomy of EFNs of $M$. azedarach should serve as baseline information to assist in ecological studies on the invasiveness of this species, as well as its potential biocontrol.

\section{Acknowledgements}

Our thanks to Ekaterina Kotina, Hester Steyn and Pieter Bester for assistance with the SEM and light microscopy, and Marietjie Stander for doing the HILIC-MS screening for sugars. We thank Christopher Lusk (University of Waikato, New Zealand), Martin Heil (Centre for Research and Advanced Studies of the National Polytechnic Institute, Mexico) and an anonymous reviewer for providing comments and suggestions that greatly improved earlier drafts of this manuscript. The institutional support of the South African National Biodiversity Institute, Pretoria, is acknowledged with thanks.

\section{Disclosure statement}

No potential conflict of interest was reported by the authors.

\section{Funding}

This study was funded in part by the University of Johannesburg, University of Pretoria, and from a National Research Foundation grant [number NRF 95675] awarded to AEvW. The funders had no role in study design, data collection and analysis, decision to publish, or preparation of the manuscript. 


\section{References}

Abdel-Hameed UK. 2014. Delimitation of Azadirachta indica A. Juss. from Melia azedarach L. (Meliaceae Juss.) based on leaf morphology. Phyton (Buenos Aires, Argent.). 83:363-367.

Ahmed S, Idris S. 1997. Melia azedarach L. In: Faridah Hanum I, van der Maesen LJG, editors. Plant resources of South-East Asia no 11. Auxiliary plants. Leiden: Backhuys; p. 187-190.

Apple J, Feener D. 2001. Ant visitation of extrafloral nectaries of Passiflora: the effects of nectary attributes and ant behavior on patterns in facultative ant-plant mutualisms. Oecologia. 127:409-416. doi:10.1007/s004420000605.

Bentley BL. 1977. Extrafloral nectaries and protection by pugnacious bodyguards. Annual Review of Ecology and Systematics. 8:407-427. doi:10.1146/annurev.es.08.110177.002203.

Bentley BL. 1983. Nectaries in agriculture, with an emphasis on the tropics. In: Bentley BL, Elias TS, editors. The biology of nectaries. New York: Columbia University Press; p. 204-222.

Bezemer TM, Harvey JA, Cronin JT. 2014. Response of native insect communities to invasive plants. Annual Review of Entomology. 59:119-141. doi:10.1146/annurev-ento-011613-162104.

Blumenthal DM. 2006. Interactions between resource availability and enemy release in plant invasion. Ecology Letters. 9:887-895. doi:10.1111/j.1461-0248.2006.00934.x.

Champagne DE, Koul O, Isman MB, Scudder GG, Towers GN. 1992. Biological activity of limonoids from the Rutales. Phytochemistry. 31:377-394. doi:10.1016/0031-9422(92)90003-9.

Dahlgren R, Van Wyk AE. 1988. Structures and relationships of families endemic to or centered in southern Africa. Monographs in Systematic Botany From the Missouri Botanical Garden. 25:1-94.

de la Fuente MAS, Marquis RJ. 1999. The role of ant-tended extrafloral nectaries in the protection and benefit of a neotropical rainforest tree. Oecologia. 118:192-202. doi:10.1007/s004420050718.

Dreistadt SH. 2012. Integrated pest management for citrus. 3rd ed. Statewide Integrated Pest Management Program. University of California: Agriculture and Natural Resources; Publication 3303.

Elias TS. 1983. Extrafloral nectaries: their structure and distribution. In: Bentley B, Elias TS, editors. The biology of nectaries. New York: Columbia University Press; p. 174-203.

Elton CS. 1958. The ecology of invasions by animals and plants. London: Methuen.

Escalante-Pérez M, Heil M. 2012. Nectar secretion: its ecological context and physiological regulation. In: Vivanco JM, Baluška F, editors. Secretions and exudates in biological systems. Berlin: Springer; p. 187-220. doi:10.1007/978-3-642-23047-9.

Evert RF. 2006. Esau's plant anatomy: meristems, cells, and tissues of the plant body-their structure, function, and development. 3rd ed. Hoboken (NJ): John Wiley and Sons. doi:10.1002/ 0470047380.

Fahn A. 1979. Secretory tissues in plants. London: Academic Press.

Fang X, Di YT, Hao XJ. 2011. The advances in the limonoid chemistry of the Meliaceae family. Current Organic Chemistry. 15:1363-1391. doi:10.2174/138527211795378254.

Feder N, O’Brien TP. 1968. Plant microtechnique: some principles and new methods. American Journal of Botany. 55:123-142. doi:10.2307/2440500.

GISD (Global Invasive Species Database). 2015. Species profile Melia azedarach; [accessed 2018 Feb 22]. http://www.iucngisd.org/gisd/speciesname/Melia+azedarach.

González-Teuber M, Heil M. 2009a. The role of extrafloral nectar amino acids for the preferences of facultative and obligate ant mutualists. Journal of Chemical Ecology. 35:459-468. doi:10.1007/ s10886-009-9618-4.

González-Teuber M, Heil M. 2009b. Nectar chemistry is tailored for both attraction of mutualists and protection from exploiters. Plant Signaling and Behavior. 4:809-813. doi:10.4161/psb.4.9. 9393.

Heil M. 2011. Nectar: generation, regulation and ecological functions. Trends in Plant Science. 16:191-200. doi:10.1016/j.tplants.2011.01.003.

Heil M. 2015. Extrafloral nectar at the plant-insect interface: a spotlight on chemical ecology, phenotypic plasticity, and food webs. Annual Review of Entomology. 60:213-232. doi:10.1146/ annurev-ento-010814-020753. 
Heil M, Rattke J, Boland W. 2005. Post-secretory hydrolysis of nectar sucrose and specialization in ant/plant mutualism. Science. 308:560-563. doi:10.1126/science.1107536.

Henderson L. 2001. Alien weeds and invasive plants: a complete guide to declared weeds and invaders in South Africa. Plant Protection Research Institute Handbook no. 12. Pretoria: Agricultural Research Council.

Hernandez LM, Tupac Otero J, Manzano MR. 2013. Biological control of the greenhouse whitefly by Amitus fuscipennis: understanding the role of extrafloral nectaries from crop and non-crop vegetation. Biological Control. 67:227-234. doi:10.1016/j.biocontrol.2013.08.003.

Jacobs M. 1961. The generic identity for Melia excelsa Jack. The Gardens' Bulletin, Singapore. 18:71-75.

Jones IM, Koptur S, von Wettberg E, Diamond S. 2016. The use of extrafloral nectar in pest management: overcoming context dependence. Journal of Applied Ecology. 54:489-499. doi:10.1111/ 1365-2664.12778.

Kautz S, Williams T, Ballhorn DJ. 2017. Ecological importance of cyanogenesis and extrafloral nectar in invasive English laurel, Prunus laurocerasus. Northwest Science. 91:214-221. doi:10. 3955/046.091.0210.

Keane RM, Crawley MJ. 2002. Exotic plant invasions and the enemy release hypothesis. Trends in Ecology and Evolution. 17:164-170. doi:10.1016/s0169-5347(02)02499-0.

Koptur S. 1994. Floral and extrafloral nectars of Costa Rican Inga trees: a comparison of their constituents and composition. Biotropica. 26:276-284. doi:10.2307/2388848.

Koptur S. 2005. Nectar as fuel for plant protectors. In: Wäckers FL, Van Rijn PCJ, Bruin J, editors. Plant-provided food and herbivore-carnivore interactions. Cambridge (UK): Cambridge University Press; p. 75-108. doi:10.1017/cbo9780511542220.004.

Lach L. 2003. Invasive ants: unwanted partners in ant-plant interactions? Annals of the Missouri Botanical Garden. 90:91-108. doi:10.2307/3298529.

Lach L, Hoffmann BD. 2011. Are invasive ants better plant-defense mutualists? A comparison of foliage patrolling and herbivory in sites with invasive yellow crazy ants and native weaver ants. Oikos. 120:9-16. doi:10.1111/j.1600-0706.2010.18803.x.

Lach L, Tillberg CV, Suarez AV. 2010. Contrasting effects of an invasive ant on a native and an invasive plant. Biological Invasions. 12:3123-3133. doi:10.1007/s10530-010-9703-1.

Larsen A, Philpott SM. 2010. Twig-nesting ants: the hidden predators of the coffee berry borer in Chiapas, Mexico. Biotropica. 42:342-347. doi:10.1111/j.1744-7429.2009.00603.x.

Lersten NR, Pohl RW. 1985. Extrafloral nectaries in Cipadessa (Meliaceae). Annals of Botany. 56:363-366. doi:10.1093/oxfordjournals.aob.a087022.

Lersten NR, Rugenstein SR. 1982. Foliar nectaries in mahogany (Swietenia Jacq.). Annals of Botany. 49:397-401. doi:10.1093/oxfordjournals.aob.a086263.

Mabberley DJ. 1984. A monograph of Melia in Asia and the Pacific. The history of white cedar and Persian lilac. The Gardens' Bulletin, Singapore. 37:49-64.

Mabberley DJ. 2017. Mabberley's plant-book. 4th ed. Cambridge: Cambridge University Press. doi:10.1017/9781316335581.

Marazzi B, Bronstein JL, Koptur S. 2013. The diversity, ecology and evolution of extrafloral nectaries: current perspectives and future challenges. Annals of Botany. 111:1243-1250. doi:10. 1093/aob/mct109.

Metcalfe CR, Chalk L. 1950. Anatomy of the dicotyledons. Vol. 1. Oxford: Clarendon Press.

Morellato LPC, Oliviera PS. 1994. Extrafloral nectaries in the tropical tree Guarea macrophylla (Meliaceae). Canadian Journal of Botany. 72:157-160. doi:10.1139/b94-021.

Nepi M. 2007. Nectary structure and ultrastructure. In: Nicolson SW, Nepi M, Pacini E, editors. Nectaries and nectar. Dordrecht: Springer, p. 129-166. doi:10.1007/978-1-4020-5937-7_3.

Nepi M, Soligo C, Nocentini D, Abate M, Guarnieri M, Cai G, Bini L, Puglia M, Bianchi L, Pacini E. 2012. Amino acids and protein profile in floral nectar: much more than a simple reward. Flora. 207:475-481. doi:10.1016/j.flora.2012.06.002.

Ness JH, Bronstein JL. 2004. The effects of invasive ants on prospective ant mutualists. Biological Invasions. 6:445-461. doi:10.1023/b:binv.0000041556.88920.dd. 
Paiva EAS, Buono RA, Delgado MN. 2007. Distribution and structural aspects of extrafloral nectaries in Cedrela fissilis (Meliaceae). Flora. 202:455-461. doi:10.1016/j.flora.2006.11.001.

Paiva EAS, Machado SR. 2005. Role of intermediary cells in Peltodon radicans (Lamiaceae) in the transfer of calcium and formation of calcium oxalate crystals. Brazilian Archives of Biology and Technology. 48:147-153. doi:10.1590/s1516-89132005000100019.

Pyšek P, Richardson DM. 2008. Traits associated with invasiveness in alien plants: where do we stand? Ecological Studies. 193:97-125. doi:10.1007/978-3-540-36920-2_7.

Rico-Gray V, Oliveira PS. 2007. The ecology and evolution of ant-plant interactions. Chicago: The University of Chicago Press. doi:10.7208/chicago/9780226713540.001.0001.

Roy A, Saraf S. 2006. Limonoids: overview of significant bioactive triterpenes distributed in plants kingdom. Biological \& Pharmaceutical Bulletin. 29:191-201. doi:10.1248/bpb.29.191.

Saentrong T. 1990. Anatomical study of Melia azedarach Linn. and M. dubia Cov. Food and Agriculture Organization of the United Nations (thesis in Thai; abstract only).

Savage AM, Whitney KD. 2011. Trait-mediated indirect interactions in invasions: unique behavioral responses of an invasive ant to plant nectar. Ecosphere. 2:106. doi:10.1890/es11-00145.1.

Smiley JT. 1978. The host plant ecology of Heliconius butterflies in northeastern Costa Rica $[\mathrm{PhD}$ thesis]. Austin: University of Texas.

Staab M, Methorst J, Peters J, Blüthgen N, Klein AM. 2016. Tree diversity and nectar composition affect arthropod visitors on extrafloral nectaries in a diversity experiment. Journal of Plant Ecology. 10:201-212. doi:10.1093/jpe/rtw017.

Stander MA, Kühn W, Hiten NF. 2013. Survey of South African fruit juices using a fast screening HILIC-MS method. Food Additives \& Contaminants, Part A. 30:1473-1484. doi:10.1080/ 19440049.2013.811545.

Stenberg JA, Heil M, Åhman I, Björkman C. 2015 Optimizing crops for biocontrol of pests and disease. Trends in Plant Science. 20:698-712. doi:10.1016/j.tplants.2015.08.007.

Swearingen J, Bargeron C. 2016. Invasive plant atlas of the United States. University of Georgia Center for Invasive Species and Ecosystem Health; [accessed 2018 Feb 22]. http://www. invasiveplantatlas.org/.

Thomas V. 1991. Structural, functional and phylogenetic aspects of the colleter. Annals of Botany. 68:287-305. doi:10.1093/oxfordjournals.aob.a088256.

Tilney PM, Nel M, Van Wyk AE. 2018. Foliar secretory structures in Ekebergia capensis (Meliaceae). Heliyon. 4:e00541. doi:10.1016/j.heliyon.2018.e00541.

Unsicker SB, Kunert G, Gershenzon J. 2009. Protective perfumes: the role of vegetative volatiles in plant defense against herbivores. Current Opinion in Plant Biology. 12:479-485. doi:10.1016/j. pbi.2009.04.001.

Van Wyk B, Van Wyk P, Van Wyk B-E. 2008. Photo guide to trees of southern Africa. Pretoria: Briza.

Walters DR. 2011. Plant defense: warding off attack by pathogens, herbivores and parasitic plants. Iowa: Blackwell. doi:10.1002/9781444328547.

Weber MG, Porturas LD, Keeler KH. 2015. World list of plants with extrafloral nectaries; [accessed 2017 Jul 1]. http://www.extrafloralnectaries.org.

Yamawo A. 2015. Extrafloral nectaries of Melia azedarach (Meliaceae): the first record for genus Melia. The Journal of Japanese Botany. 90:404-406.

Yamawo A, Tagawa J, Hada Y, Suzuki N, Heil M. 2014. Different combinations of multiple defence traits in an extrafloral nectary-bearing plant growing under various habitat conditions. Journal of Ecology. 102:238-247. doi:10.1111/1365-2745.12169.

Zimmermann JG. 1932. Über die extrafloren Nektarien der Angiospermen. Beihefte zum Botanischen Centralblatt. Abteilung A. 49:99-196. 